\title{
RENAL CELL CARCINOMA PRESENTING AS A CERVICAL MASS
}

\author{
ANTONIO C. POMPEO, HIDEKI KANASHIRO, MATHEUS N. SILVA \\ Department of Urology, General Hospital, School of Medicine, University of Sao Paulo, USP, \\ Sao Paulo, SP, Brazil
}

\begin{abstract}
The authors report a case of a 60-year-old woman presenting with a renal cell carcinoma in which the first sign leading to its diagnosis was a cervical metastasis, an uncommon site of distant disease in renal neoplasms.

The patient had an 18-month history of a progressively enlarging cervical mass at the anterior aspect of the neck. After laboratory and radiological evaluation, the cervical mass was excised, and the microscopic and immunohistochemical patterns suggested the possibility of a metastatic renal cell carcinoma. Computerized tomography of the abdomen showed a solid, $4 \mathrm{~cm}$ left renal mass. A radical left nephrectomy was performed, and the histology confirmed the suspected diagnosis. The patient received immunotherapy, and in a follow-up period of 9 months, there was no evidence of recurrent disease. It seems that head and neck metastasis of renal cell carcinoma should preferentially be treated with surgical excision because of the associated morbidity and quality-of-life issues.
\end{abstract}

Key words: kidney neoplasms; renal cell, carcinoma; neoplasms metastasis; head and neck Int Braz J Urol. 2005; 31: 151-2

\section{INTRODUCTION}

Renal cell carcinoma represents approximately $3 \%$ of all adult malignancy. The most common site of metastases is bone and lung, but it has been documented to metastasize to every organ and site in the body (1). Renal cell carcinoma is the third most common infraclavicular neoplasm to metastasize to head and neck following lung and breast carcinoma. The authors report a case of a patient who had a cervical mass as the first sign leading to diagnosis of renal cell carcinoma.

\section{CASE REPORT}

A60-year-old woman was referred to the head and neck surgery service of our hospital with an 18month history of a progressively enlarging cervical mass at the anterior aspect of the neck. Physical examination disclosed a friable, ulcerated, $20 \mathrm{~cm}$ anterior cervical mass (Figure-1). A plain radiography of the thorax was normal.

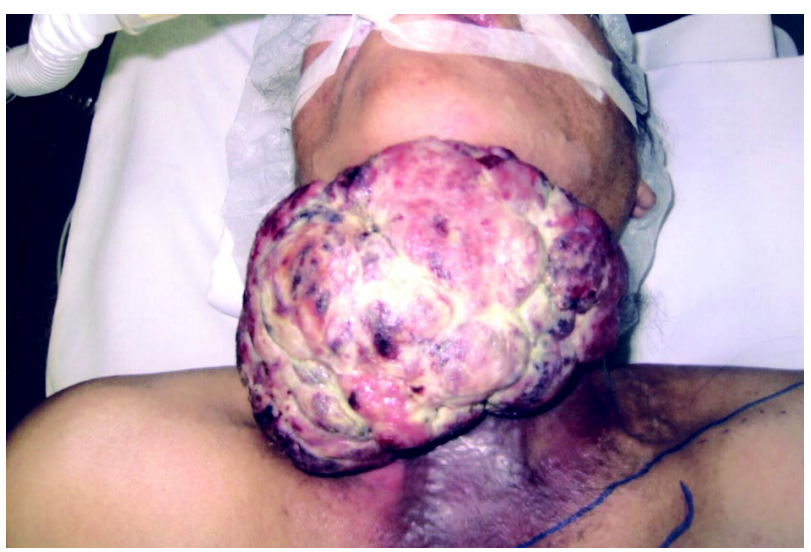

Figure 1 - Large anterior cervical mass. 
Computerized tomography of the neck showed a solid mass in the superficial space of the neck, invading pre-laryngeal muscles in the visceral space. Incisional biopsy was inconclusive.

A wedge resection of the cervical mass was performed, and a microsurgical antero-lateral thigh flap closed the wound. Microscopic examination was suggestive of metastatic carcinoma. The immunohistochemical analysis revealed a possible renal cell carcinoma.

The patient was then referred for urological evaluation. She denied any urinary symptoms. Computed tomography of the abdomen showed a solid, 4 $\mathrm{cm}$ left renal mass, which seemed restrict to renal parenchyma (Figure-2). On physical examination, there was no abdominal or flank mass. A radical left nephrectomy was then performed, and the patient received immunotherapy there after. The patient has been under continual medical observation, and there was no evidence of recurrent disease in a follow-up period of 9 months.

\section{COMMENTS}

Metastases commonly occur in renal cell carcinoma, about $40 \%$ of patients presenting with metastatic disease. The most frequent sites are lung, regional lymph nodes, bone, and liver (2). Approximately $15 \%$ of patients with renal cell carcinoma have extracranial head and neck metastases (2). In $7.5 \%$ of patient with renal cell carcinoma, the head and neck metastasis is the presenting complaint. However, only $1 \%$ of patients with renal cell carcinoma have metastases confined only to the head and neck, and solitary cervical metastatic mass, as in our patient, is rare.

Usually, the role of surgery in metastatic renal cell carcinoma is for diagnosis and debulking of disease. Excision of solitary metastatic lesion of renal cell carcinoma following nephrectomy results in a $41 \%$ survival at 2 year and $13 \%$ survival at 5 years. Pritchyk et al. (3) consider head and neck metastasis should be viewed differently because the lesion can lead to airway compromise, severe bleeding and severe disfigurement. Based on the presented case, we agree with them that depending on the site of presen-

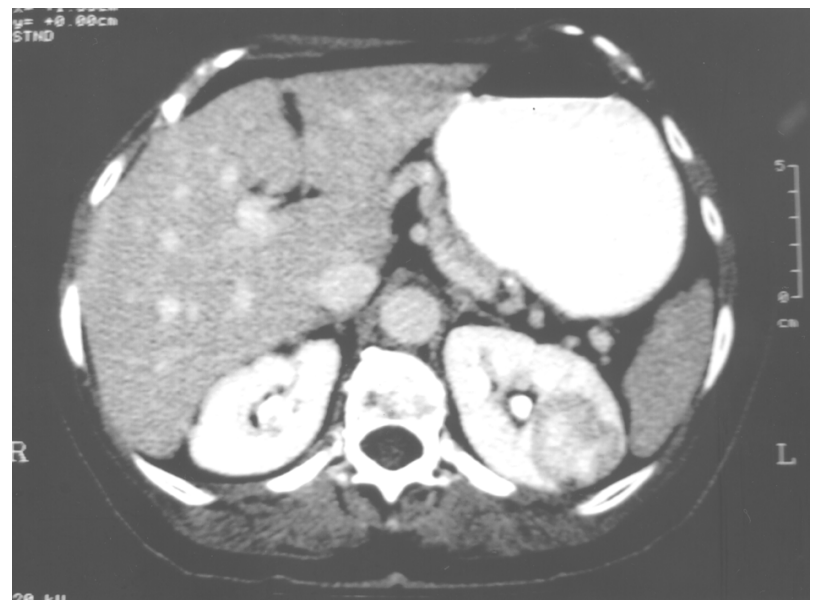

Figure 2 - Computed tomography scan of the abdomen (axial view) shows a solid, approximately $4 \mathrm{~cm}$, left renal mass, apparently restrict to renal parenchyma.

tation, local resection may improve quality of life and can provide a chance for cure in the head and neck.

The experience described herein confirms that bizarre sites of metastases from renal cell carcinoma should be kept in mind by clinicians and surgeons. Moreover, renal cell carcinoma should be considered in the differential diagnosis of any growing lesion in the head and neck.

\section{REFERENCES}

1. Savas MC, Celik, I, Benekli M, Gullu IH, Tekuzman G: Renal cell carcinoma presenting as a solitary cervical node metastasis compressing the brachial plexus. Nephron. 1998; 79: 107-8.

2. Boles R, Cerny J: Head and neck metastases from renal cell carcinomas. Mich Med. 1971; 70: 616-8.

3. Pritchyk KM, Schiff BA, Newkirk KA, Krowiak E, Deeb ZE: Metastatic renal cell carcinoma to the head and neck. Laryngoscope. 2002; 112: 1598-602.

Received: July 28, 2004

Accepted after revision: September 14, 2004

\section{Correspondence address:}

Dr. Matheus Neves Ribeiro da Silva

Rua Dr Ovidio Pires de Campos 171 / 313

São Paulo, SP, 05403 010, Brazil

E-mail: ribeiromed@hotmail.com 